\title{
PEMBUATAN PROTOTYPE SISTEM PENGENDALI LAMPU RUMAH DENGAN PERANGKAT MOBILE ANDROID
}

\author{
I G. A. K. Diafari Djuni H. ${ }^{1}$, I G A P Raka Agung ${ }^{2}$, N. Pramaita ${ }^{3}$, Made Sugiri ${ }^{4}$
}

\begin{abstract}
Android is a Linux-based operating system and is open source that can be developed independently so that more applications can be made. This application can also be integrated with other devices to control or control system is desirable. Media remote control or wireless (LAN) is a growing need for human behavior that want to move faster and farther range of location of residence. This research will be designed and built a prototype system controlling lights at home using Arduino microcontroller connected to mobile devices based on Android. Light control is done on a mobile device that is connected to the control system via WiFi Router lights. Wifi Router has sufficient coverage so that the owners of these devices can move more comfortably without having to control the lights via a switch on the wall of the house. The house lights controller circuit can adjust the lights $\mathrm{ON}$ and OFF as well as the Bright and Dim the lamp 1 and lamp 2. Lighting Control Application on mobile android devices already can set the lights on the control circuit.
\end{abstract}

Intisari - Android merupakan sistem operasi berbasis linux dan bersifat open source yang dapat dikembangkan secara bebas sehingga banyak aplikasi yang bisa dibuat. Aplikasi ini bisa juga diintegrasikan dengan perangkat lain untuk mengontrol atau mengendalikan sistem yang diinginkan. Pengendalian jarak jauh atau media tanpa kabel (wireless) merupakan kebutuhan yang semakin meningkat karena prilaku manusia yang ingin bergerak cepat dan jarak jangkau yang semakin jauh dari lokasi tempat tinggal. Pada penelitian ini akan dirancang dan dibangun prototipe sistem pengendali lampu di rumah dengan menggunakan mikrokontroler Arduino yang terhubung dengan perangkat mobile berbasis android.

\footnotetext{
${ }^{1}$ Dosen, Teknik Elektro dan Komputer Universitas Udayana, Kampus Bukit Jimbaran, Badung Bali. 80361, Tel. 0361703315 fax: 0361703315; e-mail: igakdiafari@yahoo.com

${ }^{2}$ Dosen Teknik Elektro dan Komputer Universitas Udayana, Kampus Bukit Jimbaran, Badung Bali. 80361, Tel. 0361703315 fax:0361703315; e-mail: rakaagung@unud.ac.id

${ }^{3}$ Dosen Teknik Elektro dan Komputer Universitas Udayana, Kampus Bukit Jimbaran, Badung Bali. 80361, Tel. 0361703315 fax: 0361703315; e-mail:pramaita@unud.ac.id

${ }^{4}$ Mahasiswa, Teknik Elektro dan Komputer Universitas Udayana, Kampus Bukit Jimbaran, Badung Bali. 80361, Tel. 0361703315 fax:0361703315; e-mail: sugiri@gmail.com
}

Kontrol lampu dilakukan di perangkat mobile yang dihubungkan dengan sistem pengendali lampu melalui $\mathrm{WiFi}$ Router. Wifi Router ini memiliki jangkauan yang cukup sehingga pemilik perangkat ini bisa bergerak lebih nyaman tanpa harus mengendalikan lampu melalui saklar yang ada di dinding rumah. Rangkaian Pengendali Lampu Rumah dapat mengatur lampu dalam kondisi ON dan OFF serta Cerah dan Redup pada lampu 1 dan lampu 2. Aplikasi Pengendali Lampu pada perangkat mobile android sudah dapat mengatur lampu pada rangkaian pengendali.

Kata Kunci: Android, mikrokontroler,kontrol lampu rumah,wifi

\section{PENDAHULUAN}

Perkembangan komputer seperti komputer tablet. Komputer tablet ini sudah bisa digunakan untuk berkomunikasi sehingga sulit dibedakan antara ponsel pintar dengan komputer tablet. Untuk memudahkan penulisan digunakan dengan istilah perangkat mobile. Dalam mengaktifkan perangkat telepon pintar/ponsel pintar diperlukan suatu sistem operasi. Salah satu sistem operasi yang banyak digunakan dalam perangkat telepon ini adalah sistem operasi berbasis android. Android merupakan sistem operasi berbasis linux dan bersifat open source yang dapat dikembangkan secara bebas sehingga banyak aplikasi yang bisa dibuat. Aplikasi ini bisa juga diintegrasikan dengan perangkat lain untuk mengontrol atau mengendalikan sistem yang diinginkan.

Pengendalian jarak jauh atau media tanpa kabel (wireless) merupakan kebutuhan yang semakin meningkat karena prilaku manusia yang ingin bergerak cepat dan jarak jangkau yang semakin jauh dari lokasi tempat tinggal. Mengontrol siaran televise atau alat elektronik dengan remote kontrol adalah contoh yang sering kita jumpai dalam mengendalikan sistem perangkat yang ada di rumah. Dengan alasan itu bisa dibuat model sistem pengendali lampu yang ada dirumah dengan telepon pintar/perangkat mobile

\section{MIKROKONTROLER BOARD ARDUINO}

Mikrokontroler Arduino adalah sebuah platform dari physical computing yang bersifat open source. Yang dimaksud platform dari physical computing adalah sebuah sistem atau perangkat fisik yang menggunakan software dan 
hardware yang sifatnya interaktif yaitu dapat menerima rangsangan dari lingkungan dan merespon balik. Physical computing merupakan sebuah konsep untuk memahami hubungan yang manusiawi antara lingkungan yang sifat alaminya gabungan dari system analog dengan dunia digital. Dengan konsep inilah maka system dapat diaplikasikan dalam desain - desain alat atau projek-projek yang menggunakan sensor dan microcontroller. Dan yang dimaksud dengan sifat arduino yang open source dimana tidak hanya softwarenya saja yang opensource melainkan hardwarenya pun open source. Open Source adalah diagram rangkaian elektronik arduino yang digratiskan kepada semua orang. Setiap orang bisa bebas men-download gambarnya, membeli komponenkomponennya, membuat PCB-nya dan merangkainya sendiri tanpa harus membayar kepada para pembuat Arduino. Arduino tidak hanya sekedar sebuah alat pengembangan, tetapi arduino merupakan kombinasi dari hardware, bahasa pemrograman dan Integrated Development Environment (IDE) yang canggih.IDE adalah sebuah software yang sangat berperan untuk menulis program, meng-compile menjadi kode biner dan meng-upload ke dalam memory microcontroller.

Secara umum Arduino terdiri dari dua bagian, yaitu :

1. Hardware ( papan input/output (I/O)).

2. Software (Software Arduino meliputi IDE untuk menulis program, driver untuk koneksi dengan komputer, contoh program dan library untuk pengembangan program).

Hardware pada arduino yang dimaksud berupa seperangkat system komponen yang telah terkombinasi dengan mikrokontroler sebagai otak dari sistem dan antarmuka (interface) yang akan menghubungkan system mikrokontroler dengan sistem komputer. Komponen utama di dalam papan Arduino adalah sebuah mikrokontroler 8 bit dengan merk ATmega yang dibuat oleh perusahaan Atmel Corporation. Jenis arduino yang digunakan adalah arduino uno yang memiliki mikrokontroler ATmega 328 sebagai control utamanya. Pada gambar 2 diperlihatkan contoh diagram blok sederhana dari microcontroller ATmega328 yang dipakai pada Arduino Uno.

Bagian - bagian papan PCB dari arduino uno dapat dilihat pada gambar 1

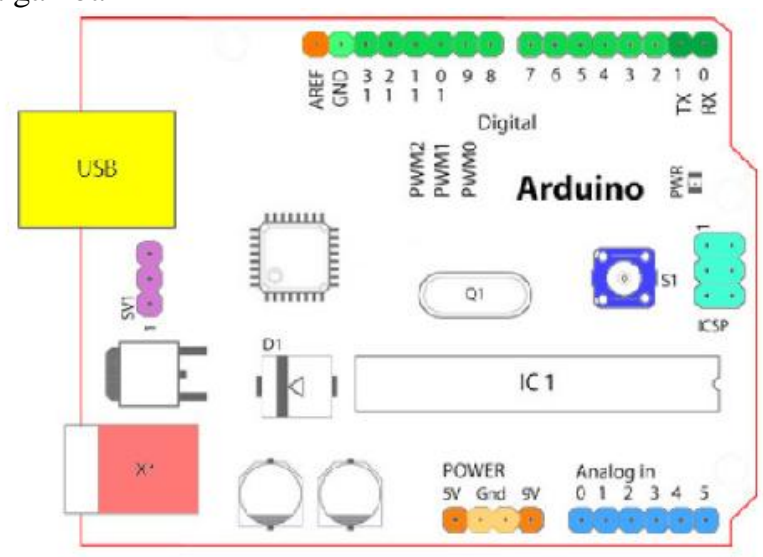

Gambar 1. Bagian bagian arduino uno [2]

\subsection{Software Arduino}

Sehubungan dengan pembahasan untuk saat ini software Arduino yang akan digunakan adalah driver dan IDE, walaupun masih ada beberapa software lain yang sangat berguna selama pengembangan Arduino.

IDE Arduino adalah software ditulis dengan menggunakan Java. IDE Arduino terdiri dari:

1. Editor program, sebuah window yang memungkinkan pengguna menulis dan mengedit program dalam bahasa Processing.

2. Compiler, sebuah modul yang mengubah kode program (bahasa Processing) menjadi kode biner. Bagaimanapun sebuah microcontroller tidak akan bisa memahami bahasa Processing. Yang bisa dipahami oleh microcontroller adalah kode biner. Itulah sebabnya compiler diperlukan dalam hal ini.

3. Uploader, sebuah modul yang memuat kode biner dari Jomputer ke dalam memory di dalam papan Arduino.

Gambar 3 adalah contoh tampilan IDE Arduino dengan sebuah sketch yang sedang diedit.

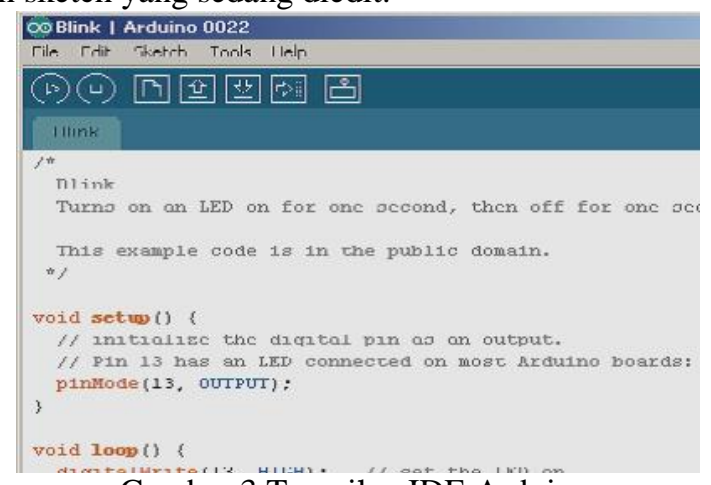

Gambar 3 Tampilan IDE Arduino

\subsection{Pengenalan android}

Android merupakan sebuah sistem operasi open source yang diperuntukan untuk perangkat bergerak (mobile device). Dikembangkan oleh Open Handset Alliance yang terdiri dari pengembang software, hardware dan provider seperti Google, HTC, Intel, Motorola, Qualcomm, T-Mobile, dan NVIDIA yang bertujuan membuat sebuah standar terbuka untuk perangkat bergerak (mobile device). Pada Juli 2005 android telah diakuisisi oleh google dan pada 5 November 2007 barulah secara resmi Android di rilis oleh Google. Dalam pengembangan aplikasi android menyediakan Android SDK (Software Development Kit) yang menyediakan tools dan API (Application Programming Interface) untuk para pengembang aplikasi dengan flatform android. [7]

\section{METODE PENELITIAN}

Metode penelitian menguraikan metode yang digunakan dalam penelitian rancang bangun ini. Adapun hal-hal yang akan diuraikan dalam bagian ini adalah mengenai perancangan perangkat keras dan perangkat lunak 


\subsection{Diagram alir rancang bangun keseluruhan sistem}

Secara keseluruhan proses penelitian ini memiliki diagram alir rancang bangun (perancangan sampai realisasi) seperti gambar 5

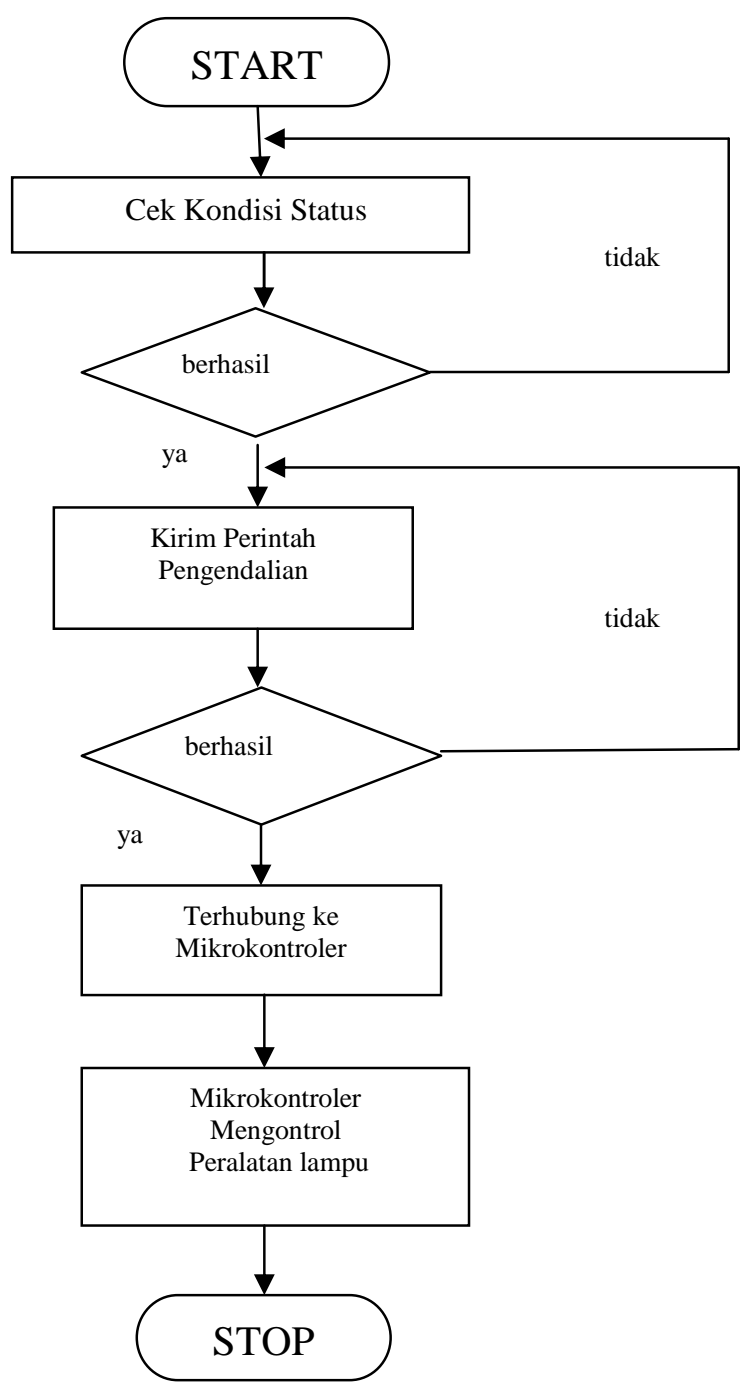

Gambar 5. Diagram alir rancang bangun keseluruhan sistem

\subsection{Perancangan Perangkat Keras}

Perancangan perangkat keras bertujuan untuk mendapatkan skema atau gambar rangkaian/perangkat keras dari alat yang akan dibuat. Perancangan perangkat keras dimulai dengan pembuatan diagram blok yang berisi blokblok penyusun alat serta hubungan fungsional antar blok. Adapun blok diagram dari alat/perangkat keras yang akan dirancang seperti gambar 6

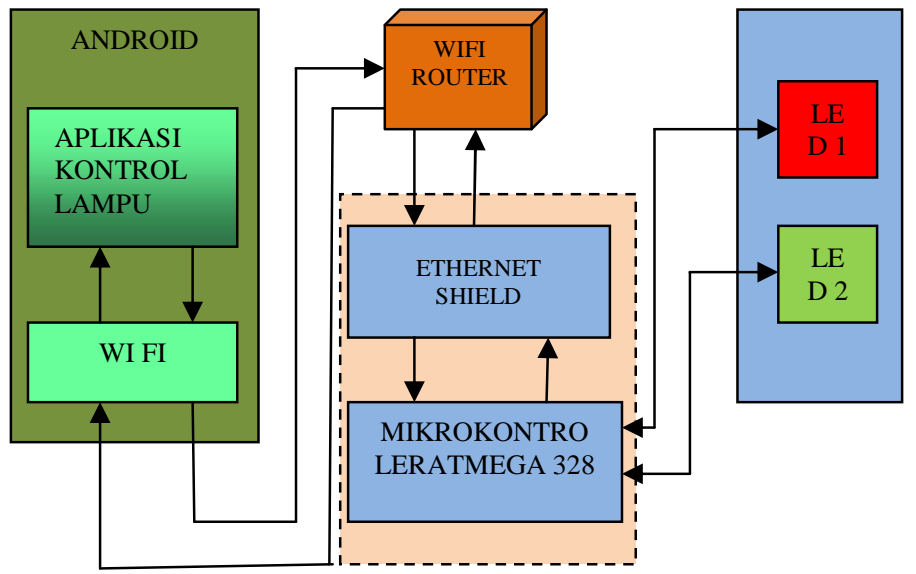

Gambar 6. Perancangan Perangkat Keras

\subsection{Perancangan Program Aplikasi Pengendali dengan Perangkat Mobile Android}

Aplikasi pada Perangkat Mobile Andorid dibuatkan suatu program yang bisa menghubungkan perangkat mobile dengan mikrokontroler. Aplikasi ini dibangun dengan menggunakan program IDE Eclipse Android Development Tools yang terdiri dari aplikasi Layout dan Activity. Perangcangan aplikasi Layout terdiri dari 4 imageButton yang merupakan alat pengendali seperti saklar manual/tombol ON dan tombol OFF untuk mengatur hidup dan padamnya lampu led. Aplikasi activity hanya menampilkan tombol ON dan OFF serta kondisi cerah dan redup.

\section{HASIL DAN ANALISIS}

\subsection{Realisasi hasil rancangan Rangkaian Pengendali Lampu Rumah}

Hasil rancang bangun prototype Rangkaian Pengendali Lampu Rumah ditunjukkan dalam gambar 7. Untuk Lampu rumah dimodelkan dengan menggunakan sebuah LED.

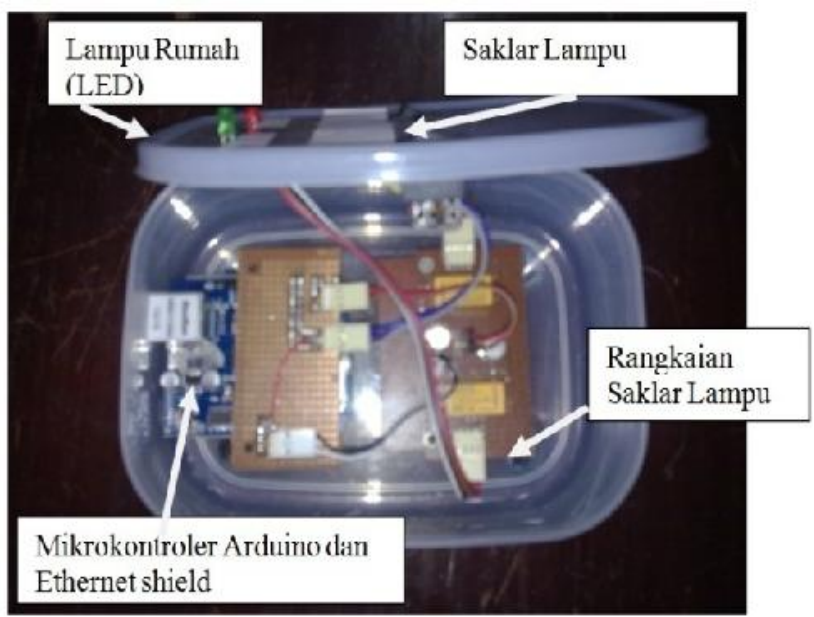

Gambar 7. Rangkaian Pengendali Lampu Rumah dengan menggunakan LED 


\subsection{Pengujian dan Pembahasan Rangkaian Pengendali Lampu Rumah}

Pengujian rangkaian pengendali lampu dilakukan dengan menggunakan dua cara yaitu pengendalian Lampu Rumah (LED) dilakukan secara manual dan pengendalian Lampu Rumah (LED) dilakukan dengan perangkat Mobile Android

\section{A. Hasil pengujian pengendalian Lampu Rumah dilakukan secara manual}

Pengujiaan dilakukan dengan menekan saklar ON dan OFF untuk lampu 1(LED warna hijau) dan lampu 2 (LED warna merah). Hasil pengukuran nilai masukan ke LED dengan menggunakan multimeter digital terlihat dalam tabel 1

Tabel 1. Kondisi Lampu Hidup (ON) atau Mati (OFF) dengan Manual

\begin{tabular}{|c|c|c|c|}
\hline No & Kondisi & Out1 & Out2 \\
\hline 1 & $\begin{array}{l}\text { LED 1 ON, } \\
\text { LED 2 OFF }\end{array}$ & $4.46 \mathrm{~V}$ & $0.01 \mathrm{~V}$ \\
\hline 2 & $\begin{array}{l}\text { LED 2 ON, } \\
\text { LED 1 OFF }\end{array}$ & $0.01 \mathrm{~V}$ & $4.47 \mathrm{~V}$ \\
\hline
\end{tabular}

Pengendalian dilakukan secara manual dengan menggunakan saklar on/off yang ada di kotak perangkat seperti yang terlihat pada gambar 7. Kondisi ini terjadi dengan mengaktifkan fungsi relay yang ada dalam rangkaian pengendali sehingga port P.2 dan P.3 mikrokontroler tidak difungsikan.

\section{B. Hasil pengujian pengendalian Lampu Rumah dilakukan dengan Komputer}

Pengujiaan dilakukan dalam keadaan ON dan OFF untuk lampu 1(LED warna hijau) dan lampu 2 (LED warna merah) serta pengujian lampu dalam keadaaan cerah dan redup. . Hasil pengukuran nilai masukan ke LED dengan menggunakan multimeter digital terlihat dalam tabel 1

Tabel 2. Kondisi Lampu Hidup atau Mati dengan Komputer

\begin{tabular}{|c|c|c|c|}
\hline No & Kondisi & Out1 & Out2 \\
\hline 1 & $\begin{array}{l}\text { LED 1 ON, } \\
\text { LED 2 OFF }\end{array}$ & $4.46 \mathrm{~V}$ & $0.01 \mathrm{~V}$ \\
\hline 2 & $\begin{array}{l}\text { LED 2 ON, } \\
\text { LED 1 OFF }\end{array}$ & $0.01 \mathrm{~V}$ & $4.45 \mathrm{~V}$ \\
\hline
\end{tabular}

Dalam kondisi ini saklar yang ada di kotak perangkat dalam posisi off. Untuk pengujian pengendalian lampu dilakukan dengan menghubung perangkat pengendali dengan komputer melalui kabel UTP. IP address di atur dalam kelas IP yang sama sehingga antara perangkat pengendali dan komputer dapat melakukan komunikasi data. Dengan software browser yang ada di komputer, dapat dimanfaatkan untuk mengakses perangkat pengendali yang sudah memiliki IP Address 192.168.0.177. Selanjutnya akan terlihat halaman web yang berisi menu untuk pengendalian lampu seperti menu on, off, tanda + (untuk menambah kecerahan lampu) dan tanda - (untuk mengurangi kecerahan lampu). Bila menu ON pada lampu 1 dipilih maka akan mengaktifkan mikrokontroler pada port P.2 dalam level tegangan $4,46 \mathrm{~V}$ yang berarti lampu (LED) 1 dalam kondisi hidup. Demikian juga untuk menghidupkan lampu 2 perangkat pengendali menggunakan mikrokontroler di port P.3.

Tabel 3. Kondisi Lampu dalam kondisi Cerah atau Redup

\begin{tabular}{|c|c|c|c|}
\hline \multirow{2}{*}{ No } & \multirow{2}{*}{ Kondisi } & LED 1 & LED 2 \\
\cline { 3 - 4 } & & Out 1 & Out 2 \\
\hline 1 & Cerah & $4.45 \mathrm{~V}$ & $4.33 \mathrm{~V}$ \\
\hline 2 & Cerah & $4.22 \mathrm{~V}$ & $3.87 \mathrm{~V}$ \\
\hline 3 & Cerah & $3.76 \mathrm{~V}$ & $3.41 \mathrm{~V}$ \\
\hline 4 & Agak Cerah & $3.31 \mathrm{~V}$ & $2.96 \mathrm{~V}$ \\
\hline 5 & Agak Cerah & $2.84 \mathrm{~V}$ & $2.50 \mathrm{~V}$ \\
\hline 6 & Agak Redup & $2.38 \mathrm{~V}$ & $2.04 \mathrm{~V}$ \\
\hline 7 & Agak Redup & $1.93 \mathrm{~V}$ & $1.58 \mathrm{~V}$ \\
\hline 8 & Redup & $1.47 \mathrm{~V}$ & $1.12 \mathrm{~V}$ \\
\hline 9 & Redup & $1.01 \mathrm{~V}$ & $0.66 \mathrm{~V}$ \\
\hline 10 & Redup & $0.55 \mathrm{~V}$ & $0.20 \mathrm{~V}$ \\
\hline
\end{tabular}

Pada tabel 3 dilakukan pengujian pengendalian lampu dalam kondisi cerah atau redup. Port P.5 dan P.6 dalam mikrokontroler arduino digunakan untuk mengendalikan tingkat kecerahan lampu. Perubahan tingkat kecerahan dilakuan dengan menambah atau menurunkan level tegangan dari output mikrokontroler. Angka yang dipakai menambah level tegangan mulai dari 0 - 255 dengan pertambahan setiap 25. Dan sebaliknya, untuk menurunkan level tegangan dilakukan penurunan secara bertahap dengan angka penurunan setiap 25 .

\subsection{Realisasi hasil rancangan Aplikasi Pengendali Lampu pada Perangkat Mobile}

Aplikasi layout dalam perangkat mobile android didesain dengan menggunakan software development tool Eclipse, yang hasilnya dapat ditampilkan dalam emulator android. Aplikasi ini sudah terpasang dalam perangkat mobile android dan diujikan. Gambar 8 menunjukkan hasil rancangan aplikasi pengendali lampu rumah.

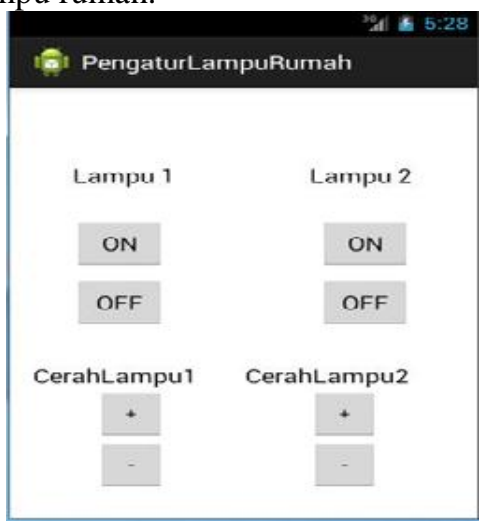

Gambar 8. Aplikasi layout Pengatur Lampu dengan emulator Android 
Tahapan pengujian ini juga dilakukan dengan menggunakan Wifi Router seperti yang terlihat dalam gambar 9. Pengujian perangkat pengendali lampu sudah menggunakan perangkat Mobile Android. Setelah melakukan pengujian setiap menu ON dan OFF serta menu tingkat kecerahan dengan tanda + (plus) dan - (minus) pada lampu 1 dan lampu 2, maka lampu 1 dan 2 dapat berfungsi sesuai dengan rancangan yang diinginkan.



Gambar 9. Rangkaian Pengendali Lampu Rumah terhubung dengan Wifi Router

\section{SIMPULAN}

Dari pembahasan dan pengujian pada bab sebelumnya dapat ditarik simpulan sebagai berikut.

1. Rangkaian Pengendali Lampu Rumah dapat mengatur lampu dalam kondisi ON dan OFF serta Cerah dan Redup pada lampu 1 dan lampu 2

2. Aplikasi Pengendali Lampu pada perangkat mobile android sudah dapat mengatur lampu pada rangkaian pengendali.

\section{UCAPAN TERIMAKASIH}

Ucapan terimakasih ditujukan kepada Lembaga Penelitian dan Pengabdian Masyarakat (LPPM) Universitas Udayana dalam Hibah Penelitian Dosen Muda Tahun 2014

\section{DAFTAR PUSTAKA}

[1]. Anggit Supriyanto ,2013, Rancang Bangun Kendali Lampu Menggunakan Mikrokontroller ATMega8535 Berbasis Android Melalui Bluetooth dan Speech Recognition,Jurusan Teknik Informatika, STMIK AMIKOM YOGYAKARTA,2013

[2]. Feri, 2011, Pengenalan Arduino, www.tobuku.com /docs/ Arduino-Pengenalan.pdf diakses tgl 24 Januari 2014

[3]. Iswanto,2011, Belajar Mikrokontroler AT89s51 dengan Bahasa C, ANDI Yogyakarta

[4]. Milette, G., Stroud, A., 2012, Professional Android Sensor Programming, John Wiley \& Sons, Inc., Indianapolis

[5]. Muhammad Ichwan, Milda Gustiana Husada, M. Iqbal Ar Rasyid, 2013,Pembangunan Prototipe Sistem Pengendalian Peralatan Listrik Pada Platform Android, Jurusan Teknik
Informatika, Institut Teknologi Nasional Bandung, 2013 http://lib.itenas.ac.id/kti/?p=2126 diakses tgl 23 Nastangin 10.02 .7857

[6]. Nastangin dan Maryanti Rahayu Ningsih,2013, Sistem Pengendali Lampu Rumah Menggunakan Wireless RF 433MHz, Jurusan Teknik Informatika, STMIK AMIKOM YOGYAKARTA,2013 http://repository.amikom.ac.id/files/Publikasi_10.02.7857.pdf diakses tgl 23 Januari 2014

[7]. Reto, M., 2009, Profesional Android Application Development, Willey, Indianapolis

[8]. Safaat, Nazruddin. 2013. "Aplikasi Berbasis Android". Penerbit INFORMATIKA: Bandung. 